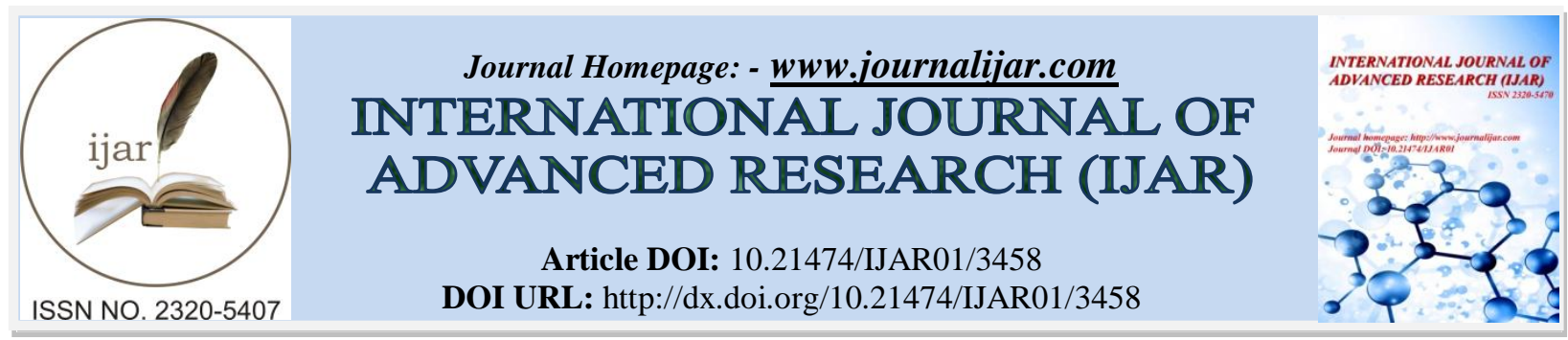

RESEARCH ARTICLE

\title{
SOME PROBLEMS AND ESPECIALLY IDENTIFICATION OF FOSSIL CORALS.
}

\author{
Yuri Ya. Latypov. \\ V. Zhirmunsky Institute of Marine Biology, National Scientific Center of Marine Biology FEB RAS Vladivostok, \\ 690041 Russia.
}

\section{Manuscript Info}

Manuscript History

Received: 18 December 2016

Final Accepted: 17 January 2017

Published: February 2017

Key words:-

Identification, fossil, phenone, rugosa,

variability

\section{Abstract}

Provides a conceptual theory of identification fossil rugosa. Discusses the possibility define the boundaries of the variability of their featured. With specific examples showing ways distinguishing consimilar and different phenones. It is shown that based on the facts already discrete phenotypes identified between the two sets of signs, one could argue about the reproductive isolation of each single species

\section{Introduction:-}

We do not work with fossil corals idea of the species as such, in the usual sense of the term; we will explore the remains of the stone specimens, samples and sample series. The first thing we do - combine them into groups of similar instances phenotypic - phenone (group of organisms isolated by analyzing the morphological anatomical characteristics). Phenone, collected in one locality (geological horizon) may represent different species or intraspecific differentiates. To be able to select the identification of alternatives, it is necessary to thoroughly examine individual variability, having fully its qualitative and quantitative analysis. Only if there is a sufficiently large number of carefully labeled specimens is possible a comprehensive analysis of the variability (Mayer, 1969; Latypov, 1984; Latypov et al, 1998).

At particularly high variability of corals and diverse, "if we know its limits, we will be able to know the boundaries of dissimilar types" (Vaughan, 1907, p. 4). The values of the individual features of corals may change 10-15 times even in the same population (Latypov, 1980; Latypov, 1984, Latypov et al. 1998). D. Hill studied the variability of coal rugosa Scotland united under one specific name 77 species and 7 genera established by previous researchers. Study in detail the variability of modern scleractinian species Stvlophora, Ch. Veron and M. Pichon clearly showed a complete series of transitions from thin-branchy to massive colonies of the species S. pistillata and brought 12 different species of five genera in the synonymy of this species (Hill. 1938; Veron \& Pichon, 1976). Yu. Latypov showed that in different sections of the microstructure of the coral septa could be holacant and rabdacant, bottoms plate could be cystiphyllid and full sub horizontal in close proximity to each other. Inside one sample (population) we can successfully trace all types of variability, including polymorphism (Latypov, 1976, 1977, 1982).

The author at rugosa has been shown that the more a series of samples, the more fully represented in them signs of variability and accurately define the boundaries of the morphological characteristics of the species. It was found that the degree of variability of traits directly increases with the number of copies in a population. With a large increase in the number of copies and variations of border populations signs are aligned, revealing the degree of volatility that characterized the specific features of each species (Fig. 1). Persistent symptoms showed no more than a 1.5-fold, 
and variable - 12-15-fold variability (Latypov, 1982, 2014). However, the identification of known or establishment of new types of a lower taxonomic categories are extremely important for both practical and theoretical biology problems, ecology and biogeography, paleontology, paleoecology and stratigraphy - science and the industries in which no univocal determine the type of impossible any successful research .

\section{Results:-}

\section{Conceptual Introduction}

Now, on several series of samples of fossil corals look at examples of different phenone recognition and influence the result of a comprehensive analysis of the variability in the separation of taxa previously made two methodological reservations. Firstly, in all its taxonomic constructs we will be guided hypodigm. Hypodigm of taxonomists at this time and for this taxon includes all instances, personally known to him at this time, considered it as an unmistakable member of the taxon. They are used collectively as a model, which concludes as the population (Simpson. 1961). Secondly, most corals grow during the whole life cycle, and, for example, fossil and modern single scleractinian may be 1000septum. During the evolution from the single rugosa also showed an increase in number of septum up 6 to 150. In this regard, assume that quantitative traits (such as the number septum, the cross-sectional dimensions of the bottoms of plates, their numbers at unit height, and so corallites) by themselves do not mean anything, but different meaning only relative and correlative connection or relationship with each other. They identified, usually only if a statistically significant number of treated material.

Phenones morphologically distinguishable

There is a sample Silurian rugosa (about 200 copies) from one biostrom capacity of slightly more than $1 \mathrm{~m}$ and a length of $30 \mathrm{~m}$. On the external shape all instances, except for two, completely indistinguishable. According to morphological characters, easily distinguishable from the first observation, the entire sample of the coral breaks down into 10-13 phenones, many of which are recognized by a well-defined and easily. But some of phenone in their characteristics do not allow firm conclusions about their affiliation to any known taxa, as well as to classify them to new taxa.

According to a well defined set of morphological traits identified three fairly distinct phenones cystiphyllid rugosa. - First - Cystiphyllidae with septa arranged just rare, not radials oriented, short spikes on the surface of the septa. Deferred sclerenchyme on the horizontal skeletal elements of the minor.

- Second - cystiphyllid with radial beaded septa. Deferred sclerenchyme abundant, sometimes in the form of broad basal rings.

- And finally, a clear cystiphyllid radials arranged rows rabdacant septa resembling normal lamellar septum. Deferred basal sclerenchyme moderate (Fig. 2).

Corals of phenones are significant differences in the structure of the septa, but do not have those in the structure of the bottoms and septa. Knowing that the horizontal skeletal elements have rugosa very changeable sign (Wedekind, 1927; Latypov, 1977, 1982), and, as a rule, reflects the intraspecific variation, we do not attach much importance to it.

Comparing each of the phenone a number of features set them apart from all known species characteristics cystiphyllid coral. On the other hand, a clear gap symptoms as poor development of septum in the same group of corals and clearly ranks radial rabdacant numerous septa the other allows the researcher to highlight the extreme phenones into separate taxa in the hope that it does not clog the biological literature has a pair of synonyms.

But do not jump to conclusions. It is necessary to examine the age and the individual variability of coral at least one phenone. The first ten copies show that in the course of ontogenesis there are significant changes in the structure of these rugosa. All holders of clear radial partitions do not have them in the initial stages of growth, sometimes up to his middle. They are randomly scattered short septal spines, sometimes grouped only on one side of the cup. Subsequently, these groups begin to form spikes and radials arranged rows of septum. Thus, the seemingly distinct morphological gap between individual phenones in the analysis of age variation was eliminated by itself.

Analysis of these corals age variability revealed that septal apparatus during ontogeny can vary from individual spikes, length $0.15 \mathrm{~mm}$ without any orientation, up to 27 rows of radials arranged spikes clearly $3.5 \mathrm{~mm}$ (Fig. 3 ). 
Also changeable structure themselves thorns, it varies from holacant to rabdacant. But for all its volatile nature of the septum, forming in the course of ontogeny, they have a surprising unity of development. The initial group of spikes begin to form first on one side of the cup, and then during the growth of the same side of the first radial spikes are laid. In this radial arrangement of septa is not identified at diameter of corallites less than $12 \mathrm{~mm}$. Horizontal skeletal elements change in ontogeny of coral from fine swollen vesicular plates to flat variously angled up to sub horizontal.

Identification of individual variability across the sample series shows that these signs are extremely variable and not fractures. They should be considered only as intra-taxa. So, it was high variability in the number of septa, their morphology and size. When corallites diameters from $13 \mathrm{~mm}$ to $22 \mathrm{~mm}$ radial orientation of sept can be clearly consistent or completely absent, and the number of rows of spines varies from 6 to 61, and not very dependent on corallites diameter. Wherein spikes themselves may be long or short, thick and thin, as a series of dots or dashes (see. Fig. 2 and 3). All signs have shown a very high degree of variability. septum length varied by 23.3 times; sixes plates bottoms - 22; fat thickness basal sclerenchyme - 24 times. The diameter of the cup corallites changed only by 1.7 times. It is a permanent was only coloration of corallites!

This wide range of phenotypic differences corals both phenones is a product of the same gene pool, because they do not detect ruptures on any basis, thus reveals the taxonomic integrity of phenones and reflects the intraspecific variation of many members of the same population. Indeed, they have exactly the same course of ontogeny the ever persistent attitude of the two polymorphic forms: single septal spines on septum at coral wall at the earliest stages; then forming on one side of the cup coral groups spikes, their radial orientation; and, finally, the appearance clearly radials oriented spikes (see Fig. 2-1 and 3-4). In principle, the same structure of horizontal skeletal elements, consisting of inflated vesicular plates, differentiated on the axial and peripheral areas. They develop the same type of deposits sclerenchyme lifelong coral, and there is a painting of the same skeletal elements. In all instances corallites painted in yellow-brown color.

No other specimen of thousands rugosa of the study area were found a painting corallites that would differ from the color of the host rock. By the way, when was detected this peculiarity of this species, it was suggested that copies of the form Cysticonophyllum dentatum (Ivanovsky 1963), similar to our species, but not having a radials oriented septum, should be painted in brown. Asked whether corallites originals S. dentatum yellowish-brown color, the Central Siberian Geological Museum has sent an affirmative answer.

Compare inter-population variation between set limits morphological variability characters species as a whole, showed flexibility and stability of its phenotypic traits as an indicator of the stability of the population system and the integrity of a single taxon, existed on a large space for a long time the Silurian period.

Phenone morphologically consimilar

Because the same biostrome there are two other phenones which slightly differ morphologically. With essentially the same structure of the skeletal elements, these coral samples at first denied signs to classify them to different taxa. At the same time almost every feature they have slight variations, yet not allow uniquely combine them into one taxon (see table).

Table:- Comparison of signs of morphologically similar phenones

\begin{tabular}{|l|l|}
\hline Phenone 1 & Phenone 2 \\
\hline $\begin{array}{l}\text { Septum are banded, reach or do not reach the axis, } \\
\text { sometimes in a weak convoluted Vortex }\end{array}$ & $\begin{array}{l}\text { Septum are banded, reach or do not reach the axis, often } \\
\text { convoluted in moderate Vortex }\end{array}$ \\
\hline The location of the septum is clearly symmetric & Location of septum pinnately-subradials \\
\hline $\begin{array}{l}\text { Home protosepta short, the opposite-a long, comes } \\
\text { to axis }\end{array}$ & $\begin{array}{l}\text { Home protosepta stands out no longer systematically, can } \\
\text { reach up to axis }\end{array}$ \\
\hline $\begin{array}{l}\text { Small septum can reach in length half radius } \\
\text { corallite }\end{array}$ & $\begin{array}{l}\text { Small septum can reach more than half the radius of the } \\
\text { corallite }\end{array}$ \\
\hline $\begin{array}{l}\text { Number of septum by when diameter 9-20 mm is } \\
\text { equal to 32 } \mathrm{x} 2-39 x 2\end{array}$ & $\begin{array}{l}\text { Number of septum by diameter 6-22 mm equal to 31x2- } \\
39 x 2\end{array}$ \\
\hline Bottoms close to cystiform & Bottoms close to cystiforn \\
\hline Dissepiments numerous small & Dissepiments numerous small \\
\hline
\end{tabular}


As the table shows, a noticeable difference corals of phenones is reduced mainly to the symmetrical arrangement of septal apparatus in one case and the absence of, at least, apparently - in another (Fig. 4.). Analysis of age variability shows that changes in the ontogeny of both phenones corals are about the same. First formed a large septum, i.e., sporadic, discontinuous septum, small partitions. With increasing diameter corallites is a further increase in the number septum both cycles. During growth of the axial ends of the spirally septum tend to curl to a greater or lesser extent. Number of septum corals both phenones fluctuates around the same range. Roughly the same behavior in all other features of both phenones, as already mentioned, in addition to the orientation and topography septum cardinal and the other septum.

When plotting the amount of septum corallites diameter (Fig. 5A) revealed a clear pattern, which imparts additional specific and, in our opinion, an essential feature that allows to distinguish the studied phenones. In corals 1st phenone new septum stopped inserted in the range of diameter sizes from 10 to $15 \mathrm{~mm}$, while the rugosa 2 nd phenone they continued to be inserted at corallites diameters of 18-20 mm. Both of these are characteristic for each phenone is not the modification, and the hereditary nature. It determines a different development of septal walls in ontogeny. Morphologically it is expressed in a clear bilaterally oriented arrangement of septa in one case and pinnately subradials - in another. Is not the same topography and the opposing major protoseptum in both cases. In this regard, numerous become clear phenotypic difference almost every feature. Live corals were different in structure and individual development gastrovascular cavity. The number, orientation septum time of termination of their insertion in the course determined by the number of life-cycle orientation, termination of education radial chambers, as well as mesenteric filaments and in the intestinal cavity of the polyp. In other words, these corals phenones different device throughout the organ systems, representing at Anthozoa physiologically isolated intestine (Villee, 1959; Beklemishev 1964; Goreau et al, 1979.; Latypov, 2016). In this case, there can be traced variously organized digestive system that was most likely due to differences in food consumption (structure, size and so forth.). Such differently arranged groups of corals is likely to be genetically determined and had concise essentic distance.

\section{Discussion:-}

Dismantling and phenones analysis lead to the need to make decisions about their attribution to certain taxa. And in the case of differing phenones were installed transitions between the most extreme forms, and these transitions are controlled in the ontogeny of a single instance. Therefore, the assignment of phenones to the same species is not in doubt. In case of similar phenones full transitions were found, on the contrary, a sign was found that distinguishes one from the other phenone. Having one sign by which two different phenones. it is useful to obtain a conclusive determination of correlations on other, less obvious signs.

Having identified the difference between the two phenones one basis, a detailed analysis can be found a lot less visible signs, which differ in these taxa. This will more likely include such taxa to different species - known Neocystiphyllum lateseptatum Ivanovsky and new N. lateseptatum (Latypov. 1979). Building a scatter plot ratio to the number of cup diameter septum showed a clear gap between the two is also on these grounds (Fig. 5B).

Getting a complete picture of the variability of other cystiphyllid phenones all samples to determine the differences as intraspecific, take all of the samples belonging to the same species and, moreover, a subspecies Holmophvllum holmi antis, described Latypov (1977) considered synonym of N. dentatum (Ivanovsky). There is likely an example of how the members of a population (polymorphic variants) have been described by various investigators as representatives of different genera. Iwanowsky (1963) has 12 copies rugosa these different safety with septal spines without radial orientation, in any case, is clearly visible. Author (Latypov 1977) had more than 70 copies. of the same population, the vast majority of which have been well expressed by the radial orientation of the septal apparatus at a late stage of growth. After studying all the samples of the seven local populations (stratigraphically consecutive populations or populations of the system) have been discovered corals with septa, varying from single spikes to very clearly radials oriented rows rabdacant septum. It traced in the course of ontogeny the same copies of corals with multiple septal spines, not orientated radials. In each population there are two well-identified forms cysisphyllid, the frequency of occurrence of one of them (more rare) was quite high (1:15), to re-consider its rate of mutation. And roughly the ratio of occurrence of different phenotypes maintained in all populations throughout the Wenlock. Thus, it reveals not only a high degree of continuous variation of characters, but also intermittent volatility, and hence two classes of ordered groups of corals at a very prominent classification criteria, representing actually polymorphs - members of the same taxon (Fig. 3), i.e., one species (Mayr, 1969; Latypov,1984) 
Here we have an example of what species of a biological phenomenon has existed at all times that this is not an invention of taxonomists and not special "paleontological" species (Simpson, 1961; Mayr,1969; Latypov et al., 1998). All the revealed facts - the same course ontogeny, development sclerenchyme similar formations, coloring elements of the skeleton, polymorphism frequency stability of all the members of this population system - indirectly point to the existence of this situation, the system homeostasis (Bernard, 1879). It was she who supported physiological stable conditions in many individuals all seven populations that existed during the Wenlock, in a clearly changeable environment. This is known to be quite complex regulatory system aimed at support constant internal environment, in terms of principle is the same not only for the members of the local population, but also for all members of the species. In this case we had more time to make sure.

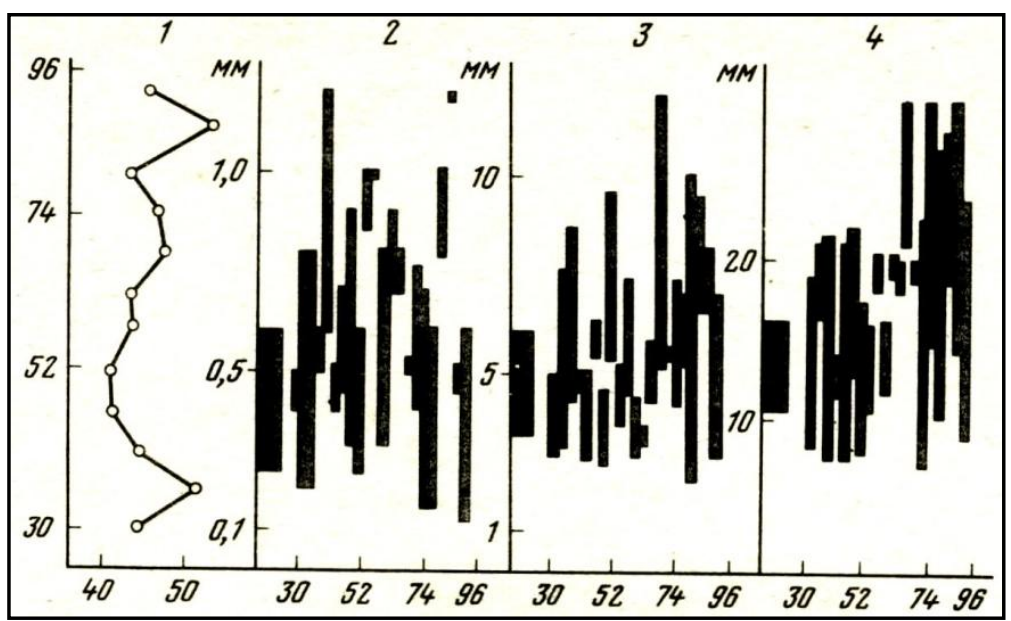

FIG. 1. Chart limits variations signs one type of coral. 1- number of septae at the same diameter, 2- width, 3length of main protoseptum, 4- diameter corallite. Ordinate dimensions. Abscissa layers cut. 2-4 - Ordinate axis line of magnitude indications one specimen.

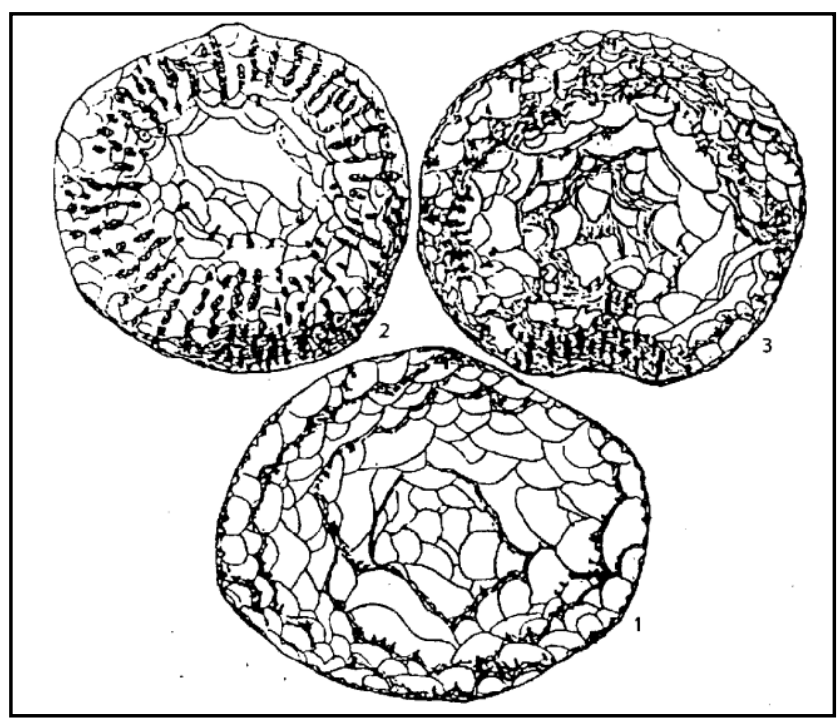

FIG. 2:- Cross-sections cystifyllid three morphologically different phenons. 1-developed individual septal spines. 2-radial ranks of septal spines, 3-rows of thorns, blending in septum. 


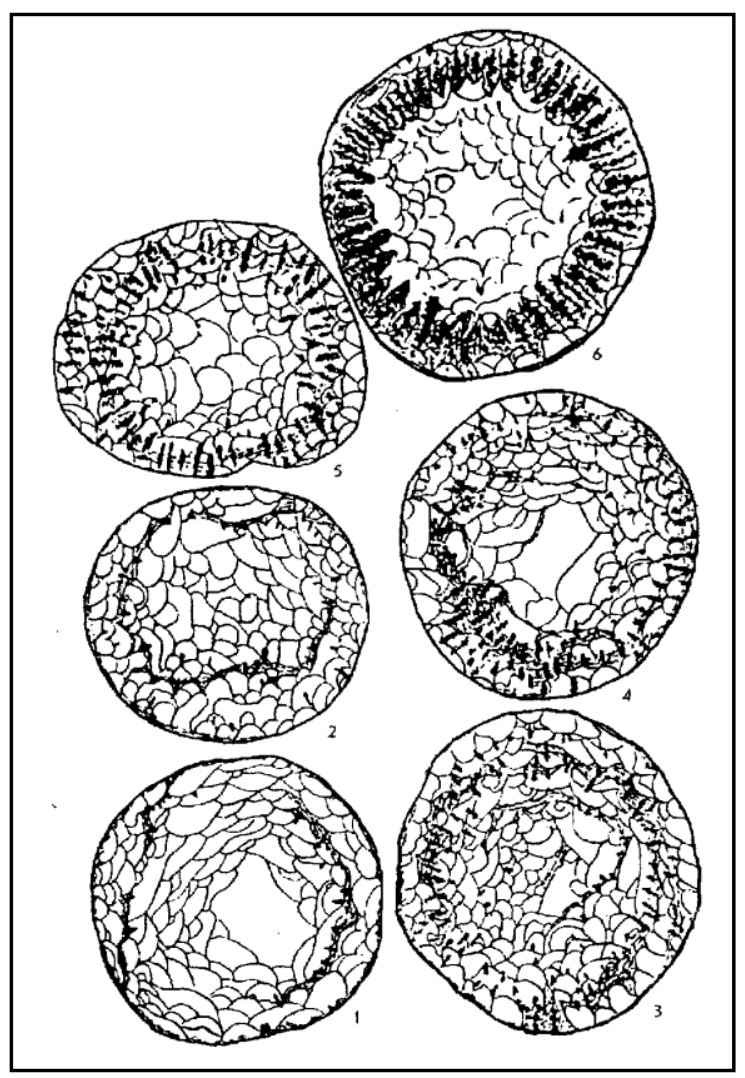

FIG. 3:- Individual variability in populations of Holophyllum dentatum from the foundation strip-pit 64 outcrops Mojero River (Sibirian). 1-6-cross sections of various corallites near the bottom of the cup. Good traces transition between extreme, individuals with poorly developed septal apparatus and specimen with numerous radial rows of thorns.

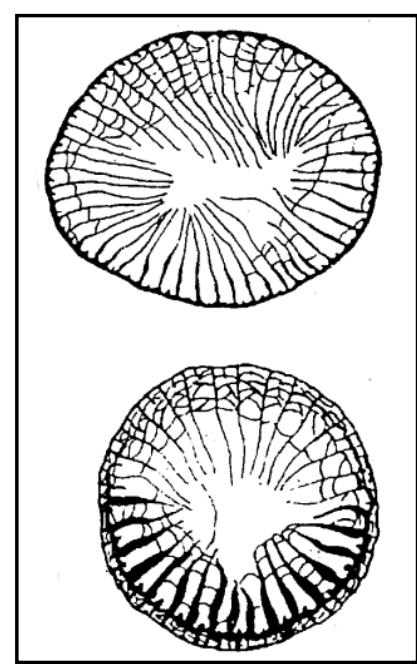

FIG. 4:- Cross-section of corals far in the sibling relation. Pseudophaulactis - late Llandovery, Caninia- early Carboniferous. 

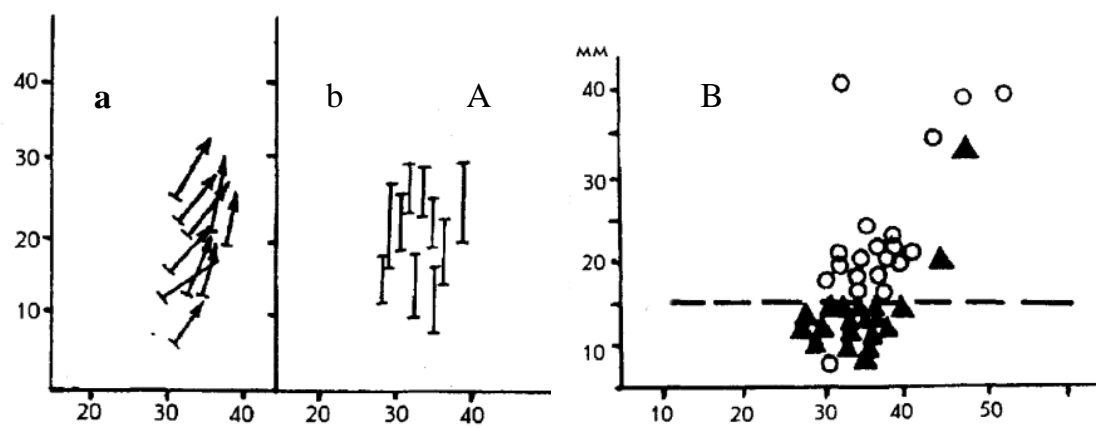

FIG. 5:- Dependence of septae of corallite diameter (A). With the same class units number of corallites diameters septae phenona (a) continues to grow and remains constant in phenone (b). Division number of septae two species of cistyfiillid based on the size of the diameter of the corallites (B), - Neocysphillum simmetricum, o-

N.lateseptatum, the dashed line is the best separation. Ordinata -corallite diameter, mm, Abscissa - is the number of septae.

\section{Conclusion:-}

By comparing samples from different populations, spatial or temporal, taxonomist looking for information that would help to decide where to put these populations - to the same or different taxa. The issue of full identity population in this never arises, for population genetics for a long time to convince us that there is a world of two completely identical individuals, even among identical twins, not to mention the identical populations (Mayr, 1969; Dobzhansky et al., 1977; Thorpe \& Sole-Cava, 1994; Fukami, 2008). Therefore, the detection of statistically significant differences for any researcher certain groups of organisms - a self-evident matter.

When working with corals with extreme variability of almost all signs and. As a rule, polytypic species often gets question - if large enough differences between the samples (populations), allowing them to consider different types? In most cases we have isolated geographic or stratigraphically allopathic populations (Latypov et al., 1998; Manchenko et al., 2000; Baker, 2006). The criterion of reproductive isolation in pure form unfortunately, we can not use. And besides, to cross two or experimental specimens of suspected species we first must establish that this particular one or two related species, and this is our main problem. It remains to rely on probable evidence that reproductive isolation is correlated with the a certain degree of phenotypic outwardly visible difference and fairly constant within a given taxonomic group, i.e., to act on the reverse. If detected within a given taxon group is quite clear morphological differences, with good signs of a break, then we can assume that these groups - good views.

Thus, the problems encountered in the establishment of intra-and intraspecific differences identified morphophisiological, ecological and Ethological means, can be solved by using biochemical, cytogenetic, electrophoresis studies. But in any case, the original conclusion about the similarities or the differences between taxa is done based on the absence or presence of the unfilled gap in those or other signs, identification and comparison of the specific characteristics of each taxon. Then it turns out what biological reasons cause the differences and similarities of traits. And based on the facts already discrete phenotypes identified between the two sets of signs, one could argue about the reproductive isolation of each single species (Mayr, 1969; Latypov, 1984; Latypov et al., 1998; Manchenko et al., 2000, Latypov 2014, 2015).

\section{References:-}

1. BEKLEMISHEV, V. N. 1964. Osnovy sravnitel'noi anatomii bespozvonochnyh. Promolfologia.

2. M.: Nauka, 433. (In Russian)

3. BERNARD, C. 1878-1879. Lecons sur les phenomenes de la vie communs aux animaux et aux

4. vegetaux . Paris, Bailliere et fils, 2 Tomes, 466.

5. DOBZHANSKY, T., AYALA, F. J., STEBBINS, G. L. and VALENTINE, J. W. 1977.

6. Evolution. San Francisco,

7. FUKAMI, H. 2008. Short review: molecular phylogenetic analyses of reef corals Galaxea.

8. Journal of Coral Reef Studies, 10: 47-55.

9. GOREAU, T. F., GOREAU, N. I. and GOREAU, T. J. 1979. Corals and coral reefs. Scientist

10. American 241: 110-120.

11. HIl1, D. 1938-40. A Monograph of the Carboniferous Rugose Corals of Scot land. - Paleontogr. 
12. Soc. Loпdoп, 91, 92, 94, 204.

13. IWANOWSKY, A.B.. 1963. RugosaOrdovician and Silurian Sibirian platforva. M., Izd-vo AN

14. USSR, 159. (In Russian)

15. LATYPOV, Yu. Ya. 1975. Rugosa or Tetracoralla? Palaeontological Journal, 3, 133-135.

16. 1979. Solitary diafragmatophore rugosa from North Asia. Third Intern. Symp. Fossil

17. CNIDARIA. Warszawa, 46-48.

18. 1982. Solitary diafragmatophore corals of North Asia. M.: Nauka, 116.

19. 1977. Solitary cystifore corals North Asia. Novosibirsk, Nauka, 79.

20. 1980. A variability of Acropora.Sec.Intern.Symp.biol.of tropical water. Port Morsby, 36.

21. 1984. The oldest solitary corals and their principles of Systematics, M.: Nauka, 94.

22. 2014. Scleractinian Corals of Vietnam. Science Publishing Group, I-XXXIV, 1-481.

23. 2016. Particular Qualities of Identification and Taxonomy of Some Scleractinian (Scleractinia:

24. Astrocoeniina) Family Acroporidae Verrill, 1903, International Journal of Marine Science,

25. 6(16): $1-8$.

26. LATYPOV, Yu.Ya., DAUTOVA, T.N. and MOSHENKO, A.V. 1998. The principles and

27. Methods of the CNIDARIA classification. Vladivostok, Dalnauka, 244.

28. MANCHENKO, G. P, DAUTOVA, T. N.and LATYPOV Yu. Ya. 2000. High level of genetic

29. divergence between sympatric color morphs of the littoral sea anemone Anthopleura

30. oriennalis (Anthozoa: Actiniaria). Biochemical Systematics and Ecoljgy. 28: 737-750.

31. SIMPSON, G. G. 1961 . Principles of Animal Taxonomy. NY, 249.

32. THORPE, J. P. and SOLE-CAVA, A. M. 1994. The use of allozyme electrophoresis in

33. invertebrate systematic. Zoologica Scripta., 23: 3-18.

34. VAUGHAN, T. W. 1907. Recent Madreporaria of the Hawaiian Island and Laysan. Bulletin

35. U.S. Natural Museum, 59(9): 1-427.

36. VERON, J. E. N. and Pichon, M. 1980. Scleractinia of Eastern Australia. Part 3. Families

37. Agaraciidae, Siderastreidae, Fungiidae, Oculinidae, Merulinidae, Mussidae, Pectiniidae,

38. Caryophylliidae, Dendrophylliidae. Australian Institute of Marine Science Monograpgy, IV(1): 471.

39. VILLEE, C. A. (1954). BIOLOGY. Saunders, 730.

40. WEDEKIND, R. 1927. Die Zoantharia Rugosa von Gotland (bes. Nordgotland). - Sveriges geologiska undersökning. Ser.C, 19: 94. 